\title{
The Selection of Alternative Substrates for Medicinal Mushroom Cultivation
}

\author{
Elvira F. Solomko E̊ Marharyta L. Lomberg
}

M.G. Kholodny Institute of Botany, National Academy of Sciences of the Ukraine, Kiev, Ukraine

For the present only Agaricus bisporus (J.Lge) Imbach and Pleurotus ostreatus (Jacq.: Fr.) P.Kumm. are widely cultivated in the Ukraine. However, interest in Lentinus spp., Ganoderma spp., and other mushrooms with known medicinal properties has increased. In our investigations, special attention was paid to mushroom strains that performed well on non-wood substrates from agricultural waste.

Using a complex of physiological characteristics, including growth rate of mycelia on agar and liquid media, growth and fructification on different lignocellulosic substrates were selected from some strains of such medicinal mushrooms as Agrocybe aegerita (Brig.) Singer, Auricularia spp., Flammulina velutipes (W.Curt.: Fr.) P. Karst., Ganoderma lucidum (W.Curt.: Fr.) P. Karst., Grifola frodosa (Dicks.: Fr.) S.F. Gray, Hericium erinaceus (Bull.: Fr.) Pers., Hypsizigus marmoreus (Peck) Bigel., and Lentinus edodes (Berk) Singer. Suitable agar culture media were used, and generation spawn media were found. The maximal growth rate of mycelium $(12 \mathrm{~mm} /$ day $)$ was observed for a selected strain of Ganoderma lucidum on wheat agar medium ( $\mathrm{pH} 6.0)$ at $28^{\circ} \mathrm{C}$. The mycelium growth rates of other mushrooms did not rise above $8 \mathrm{~mm} /$ day.

It is important that optimum-value $\mathrm{pH}$ media for growth mycelium of Hypsizygus marmoreus, Auricularia polytricha, and Grifola frondosa appeared above than 6.5. It should be noted that substrates for cultivation should include calcium carbonate to effectively raise $\mathrm{pH}$. Investigations showed that inoculation of sterilized grain or sawdust with submerged liquid mycelium is the most efficient path of spawn production, especially for slowly growing medicinal mushrooms such as Grifola frondosa, $H_{y p-}$ sizygus marmoreus, and Lentinus edodes.

For small-scale cultivation, different formulas of sawdust and alternative substrates from agricultural wastes, including wheat straw, cornstalks, shive of flax, buck-wheat shell, and husks of sunflower seed (HSS), were used. In accordance with the obtained results, the HSS substrate was one of the most suitable for the cultivation of Agrocybe aegerita, Auricularia polytricha, Flammulina velutipes, Ganoderma lucidum, Hericium erinaceus, Lentinus edodes, and Hypsizygus marmoreus selected strains as well as for the gourmet Oyster mushrooms, including P. ostreatus, $P$. citrinopileatus Singer, P. sajorcaju (Fr.) Singer ( $=$ P. pulmonarius (Fr.) Quèl.), and $P$. djamor (Fr.) Boedjin. For various combinations of HSS substrate, we received a heavier yield of fruit bodies in comparison with supplemented sawdust (beech) substrates. Our results reveal new perspectives on the development cultivation technology for new Ukrainian mushroom species, not only on sawdust but also on alternative substrates. 